Original Research Paper

\title{
Effect of Curcumin and Physical Training on the Brain and Motor Performance of Rats with Cerebral Ischemia
}

\author{
${ }^{1}$ Karine Sthéfany Serpa Amaral Dias, ${ }^{2}$ Jonas Augusto Ramos, ${ }^{2}$ Bruno Mattiello Gomes, \\ ${ }^{1}$ Amanda Augusta Santos, ${ }^{2}$ Andressa Vallotti Balieri, ${ }^{2}$ Bethânia Ferreira Nascimento, \\ ${ }^{2}$ Luiz Guilherme Barbosa, ${ }^{1}$ Renan de Araújo Costa, ${ }^{2}$ Vinícius Sacramento Resende, \\ ${ }^{2}$ Yuri César Silva, ${ }^{1}$ Flávia Carmo Horta Pinto and ${ }^{2}$ Laila Cristina Moreira Damázio \\ ${ }^{1}$ Department of Natural Sciences, Dom Bosco Campus, \\ Federal University of São João del-Rei, São João del-Rei, MG, Brazil \\ ${ }^{2}$ Department fo Medical, Dom Bosco Campus, Federal University of São João de-Rei, São João del-Rei, MG, Brazil
}

\author{
Article history \\ Received: 18-12-2018 \\ Revised: 21-01-2019 \\ Accepted: 24-04-2019 \\ Corresponding Author: \\ Laila Cristina Moreira Damázio \\ Department fo Medical, Dom \\ Bosco Campus, Federal \\ University of São João de-Rei, \\ São João del-Rei, MG, Brazil \\ Tel: +55 32 3379-5572 \\ E-mail: lailacmdamazio@gmail.com
}

\begin{abstract}
Brain ischemia is the second most deadly disease in the world and it has already been proven that mild and moderate physical exercises minimize the deleterious effects of this disease on the brain. Curcumin has also been considered a neuroprotective substance. Therefore, the goal of this study was to evaluate the effects of high-resistance training and curcumin on the brain and motor performance of rats with cerebral ischemia using a model of bilateral common carotid artery occlusion. Functional tests were performed to analyze rats' motor performance, namely parallel bar test and misstep test. For nerve tissue analysis, Nissl staining and neuronal counting were performed in the cerebral cortex, striatum and hippocampus of the brains. Two protocols of high-intensity physical training were performed for six weeks, five days a week, from 20 to $40 \mathrm{~min}$. The results demonstrated that there were significant differences in the parallel bar test and misstep test regarding the number of errors committed by the trained animals in comparison to the sedentary ones and the group that received curcumin. With respect to the number of neurons in the cortex and striatum, a lower neuronal density was observed in the trained animals. Thus, the animals of the sedentary group and the group that received curcumin exhibited better motor performance and higher neuronal density in the areas assessed, demonstrating that high-intensity physical exercise increased brain injury and worsened animals' motor performance.
\end{abstract}

Keywords: Cerebral Ischemia, Curcumin, Exercise, Neuroprotection

\section{Introduction}

Cerebral ischemia is the second most deadly disease in the world. It can cause great motor, sensory and systemic deficiency (Sociedade Brasileira de Doenças Cerebrovasculares; Pinheiro, 2011; Trindade et al., 2011). It is extremely important to study the molecular mechanisms involved in the excitotoxicity process in cerebral ischemia in order to determine the neuroprotective factors in this injury (Zhang et al., 2012).

Bilateral Common Carotid Artery Occlusion (BCCAO) is a type of experimental animal model that allows the reproduction of the ischemic event by inducing hypoxia with cerebral reperfusion. It causes great damage of the brain tissue due to oxidative stress and glutamate excitotoxicity (Tardini et al., 2003; Telles et al., 2014).

Interventions that make it possible to alleviate the deleterious effects of cerebral ischemia are extremely important in the neurobiology field (Damázio et al., $2014 ; 2015)$. The practice of light physical exercises before cerebral ischemia reduces the area of ischemic injury and increases the collateral irrigation of the brain (Zhang et al., 2012; Damázio et al., 2014; 2015). However, it is still controversial whether the practice of high-resistance exercises would further benefit the brains of these animals by decreasing the ischemic area. In addition to having intensity above the anaerobic threshold, high-intensity exercises are characterized by 
increasing resistance to muscle fatigue and promoting various physiological changes (ACSM, 1998).

Some compounds and extracts are being used as neuroprotective substances in the brains of animals with Alzheimer's disease (Ringman et al., 2012) and cerebral ischemia (Kim et al., 2012), obtaining efficient outcomes in the reduction of neuronal tissue damage (Matteucci et al., 2011). Curcumin is a component extracted from Curcuma longa rhizomes and has numerous biological and therapeutic effects (Xie et al., 2009). It decreases the neuroinflammatory process and some studies have demonstrated its benefit in the decrease of B-amyloid plaques in Alzheimer's disease (Kulkarni and Dhir, 2010). Some studies have assessed the effects of curcumin on cerebral ischemia and demonstrated its neuroprotective effect in this disease (Telles et al., 2014; Kim et al., 2012).

This way, the goal of the present study was to evaluate the effects of high-resistance physical training and curcumin on the brain and motor performance of rats with cerebral ischemia using a BCCAO model.

\section{Materials and Methods}

In the present study, we used 36 male Wistar rats. They were 40 days old and had an average weight of 250 g. These animals were kept in cages, with free access to water and feed, 12-hour photoperiod, room temperature between 21 and $22^{\circ} \mathrm{C}$ and relative humidity of $60-70 \%$. They were weighed at 40 days (at the beginning of the experiment), at 76 days (before the surgical procedure) and at 81 days (shortly after surgery).

The animals were divided into the following groups for the analysis of motor performance: Six animals submitted to injections of intraperitoneal curcumin and high-intensity resistance exercises (TIC-1); six animals submitted to high-intensity resistance training (TI-1); six animals in the sedentary group (S); six animals in the group submitted to intraperitoneal curcumin and sedentariness (CS); six animals submitted to high-intensity exercise, strength exercise and intraperitoneal curcumin (TIC-2); and six animals submitted to high-intensity training and strength exercises (TI-2). After BCCAO surgery, the groups were subdivided into animals with cerebral ischemia and those without cerebral ischemia.

The animals of the groups treated with curcumin (curcrumin Sigma-Aldrich) received during the whole period of physical training, per day $25 \mathrm{mg} / \mathrm{kg}$, through intraperitoneal injections (Telles et al., 2014).

The physical training initially consisted of an adaptation period in the ladder for three days, with three daily attempts and no load. In the first adaptation attempt, they remained at a distance of $35 \mathrm{~cm}$ from the housing chamber; in the second attempt at a distance of $55 \mathrm{~cm}$ (from the center of the ladder) and at the third attempt at a distance of $110 \mathrm{~cm}$ from the chamber (Hornberger Jr. and Farrar, 2004; Peixinho-Pena et al., 2012; Cassilhas et al., 2013).

After the adaptation period and prior to surgery, the animals of the trained groups were submitted to exercises in the ladder for four weeks, five days a week, for about twenty minutes. The high-intensity training for muscle strength gain (training 1) consisted of performing eight climbing series containing eight to twelve repeated movements in each series to reach the housing chamber. In the first and second series, we used a load of $50 \%$ of the total body mass of the animals. In the third and fourth series, we used a load of $75 \%$. In the fifth and sixth series we used a load of $90 \%$ and, in the seventh and eighth series we used $100 \%$ load. The interval between the series was 60 seconds, so that the animals could rest in the housing chamber. An additional load of $10 \mathrm{~g}$ was added to each training session if $100 \%$ load of the animals' body weight was easily overcome (Peixinho-Pena et al., 2012). In the high-intensity resistance training (training 2), the main difference was that the series varied weekly according to the weight of the animals. In the first week, the animals climbed with $50 \%$ load, in the second week with $75 \%$ load, in the third week with $90 \%$ and in the fourth week with $100 \%$ load. The weight was used in the proximal portion of the tail, where the weight in cylindrical format was attached with a stainless steel cable to the rubber band (Peixinho-Pena et al., 2012; Cassilhas et al., 2013).

Two different motor tests (misstep test and parallel bar test) were applied at 40 days (beginning of the experiment) and at 76 days (after the physical training) by three trained evaluators to analyze the animals' motor performances, considering the mean of the errors made by the rats in these two functional neurological tests. The misstep test lasted three minutes and was performed on a $100 \times 50 \mathrm{~cm}$ grid with $3 \times 3 \mathrm{~cm}$ grid interval $\left(9 \mathrm{~cm}^{2}\right)$. Errors were considered when the animals' feet passed through the grid (Ding et al., 2002; 2004; Lim et al., 2008). The parallel bar test consisted of two wooden platforms joined by $115 \mathrm{~cm}$ metal bars and the animals were forced to walk on them (with a low intensity aversive stimulus) for five minutes. Errors were considered when the animals placed both legs on the same bar, or when they passed the legs between the two bars or outside them (Ding et al., 2002; 2004).

After the physical training, we performed the BCCAO surgery (81 days) with a median incision in the neck region, where the right and left common carotid artery was occluded with the steel clip for 15 minutes. After the occlusion period, we performed encephalic revascularization with suture of the medial incision. After the BCCAO surgery, the animals were kept in a place with free access to water and feed and controlled body temperature. The animals were monitored during the three postoperative days. 
After the three postoperative days, the animals received intraperitoneal injection of $1 \%$ ketamine $(30$ $\mathrm{mg} / \mathrm{kg}$ ) and xylazine $(4 \mathrm{mg} / \mathrm{kg})$. Then, the brains were removed and sliced in sections of $1 \mathrm{~mm}$ in the coronal plane. The slices were paraffinized and the sections were stained at 3.20, 0.20 and $-2.80 \mathrm{~mm}$ from the bregma. These sections were again sectioned (Leica ${ }^{\circledR}$ rotating microtome, model RM2255), thus obtaining slices of 5 $\mu \mathrm{m}$ thickness, followed by deparaffinization and hydration in a decreasing alcoholic series. Then, they were stained with cresyl violet (Sigma-Aldrich) at $0.5 \%$ for $30 \mathrm{~min}$, in order to label the Nissl corpuscles present in the neuronal cytoplasm. Subsequently, we assembled and analyzed the histological slides (Scorza et al., 2005).

After tissue processing and slide assembly, we obtained three images of each histological section using the Motic Images Plus 2.0 software and a digital camera (Moticam 580) coupled to the microscope with 100x magnification (Nova Optical Systems 1801). The selected images were analyzed using the Image $\mathbf{J}$ software (Image-Pro Plus, version 4.5, Windows 98). We obtained the neuronal number of each histological section using the stereology grid in the count. The analysis was performed in the two cerebral hemispheres, in specific regions of each section with respect to bregma, as previously described.

We used one-way ANOVA test followed by Tukey's post-hoc test, considering a significance level of $p<0.05$ for the analysis of the neuronal number, whereas for the analysis of the animals' motor performance we used paired $\mathrm{t}$ test is required for withingroup comparison (before-after), considering $p<0.05$. The results were expressed as mean \pm standard error of the mean (SEM).

\section{Results}

Regarding the number of errors committed before and after the experiment, the groups S, TIC-1 and CS exhibited a significant difference in the number of errors committed at the end of the experiment $(p<0.05)$. They obtained a reduction of $7.5(p<0.001), 4.5(p=0.043)$ and 3.4 errors $(p=0.0002)$, respectively (Fig. 1).

There was also a significant decrease in the number of errors committed in the groups, before and after the experiment, in the parallel bar test. The TI-1 group had a decrease of 4.5 errors $(p=0.0399)$, the decrease in the group $\mathrm{S}$ was of 6.3 errors $(p=0.0009)$ and in the group TIC- 1 it was of 5.4 errors $(p=0.05)$, as shown in Fig. 2.

The analysis of the total mean of neurons in the cerebral cortex of the groups indicated a significant difference $(p=0.004 ; \mathrm{F}=4.54)$. The means of the groups were: $\mathrm{CSI}=28 \pm 1.6182 ; \mathrm{CSS}=23 \pm 2.291)$; $\mathrm{SI}=$ $23.5 \pm 2.6333$; $\mathrm{SS}=20.5 \pm 3.0185$; TI- $=18 \pm 1.5832$; TS-

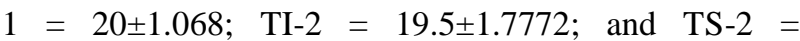
$13.5 \pm 2.3126$.
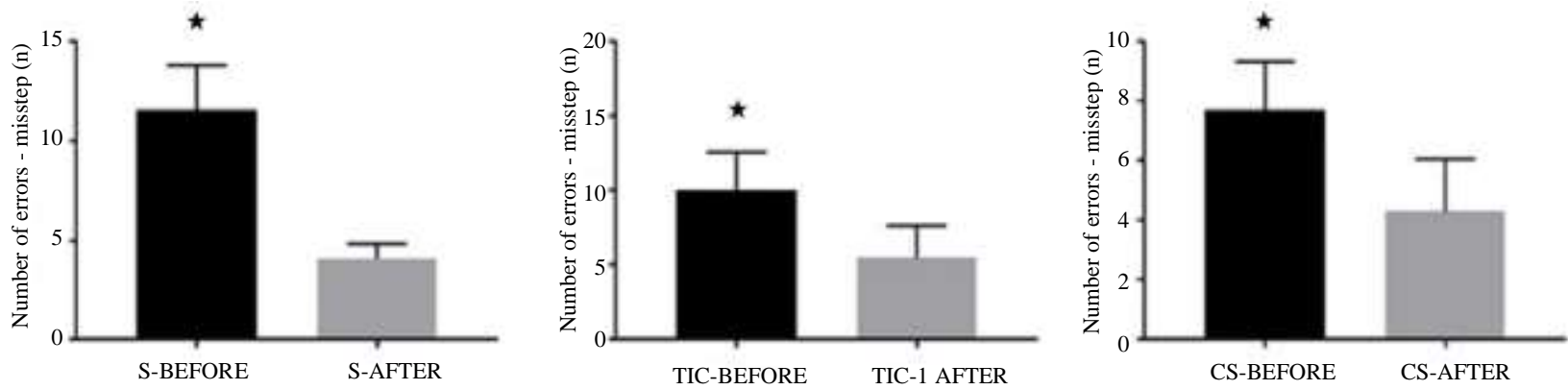

Fig. 1: Mean of errors committed before and after in the misstep test between the groups S, TIC-1 and CS, according to the paired t test is required for withingroup comparison (before-after) $(p<0.05)$
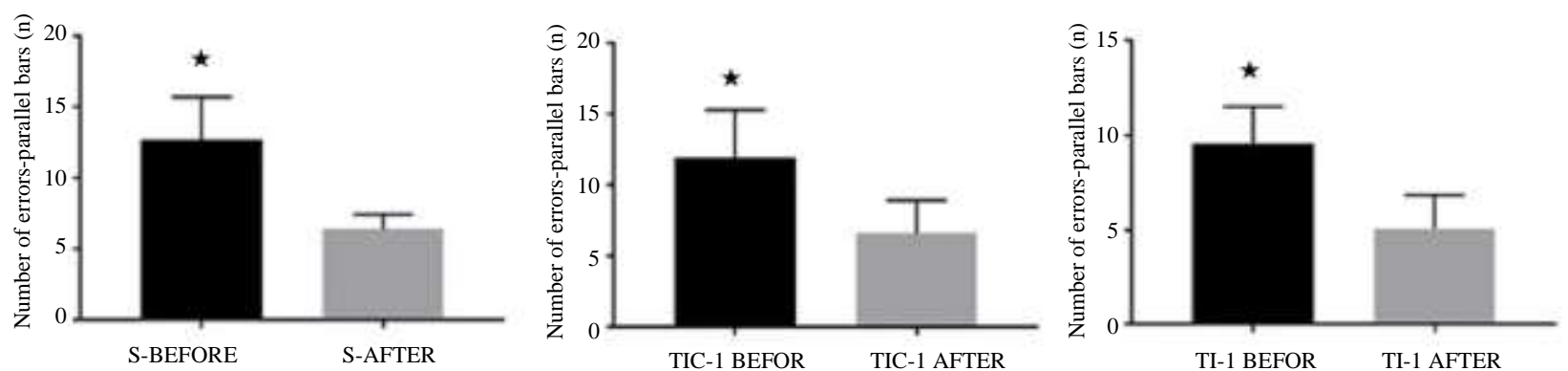

Fig. 2: Mean of errors before and after the parallel bar test between the groups S, TIC-1 and TI-1, according to the paired t test is required for withingroup comparison (before-after) $(p<0.05)$ 

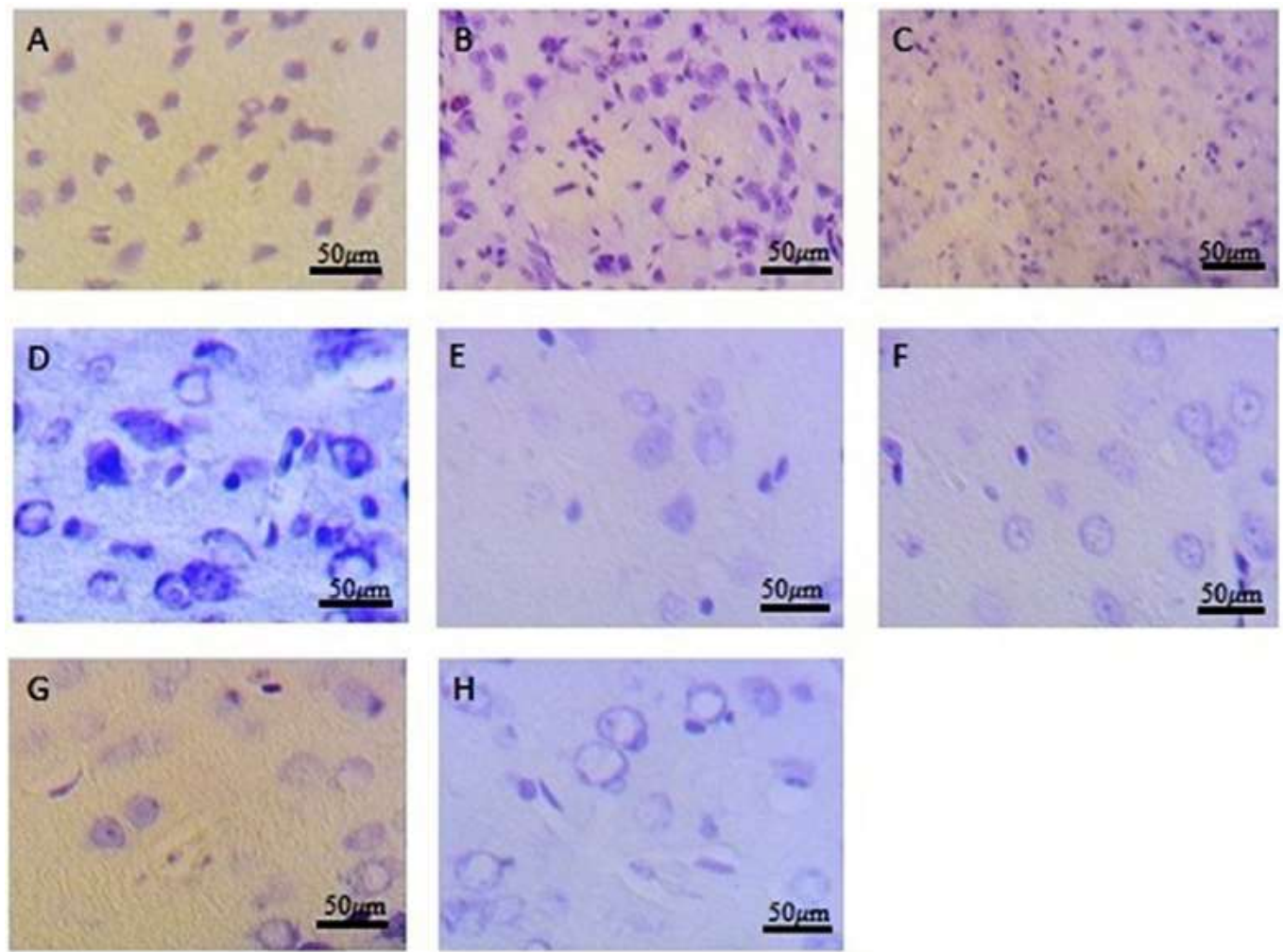

Fig. 3: Photomicrography of the $5 \mu \mathrm{m}$ sections of the rats' cortex in the groups CSI (A), CSS (B), SI (C), SS (D), TI-1 (E), TS1 (F), TI-2 (G) and TS-2 $(\mathrm{H})$, respectively. Scale bars represent $50 \mu \mathrm{m}$ (magnification: $\times 100)$
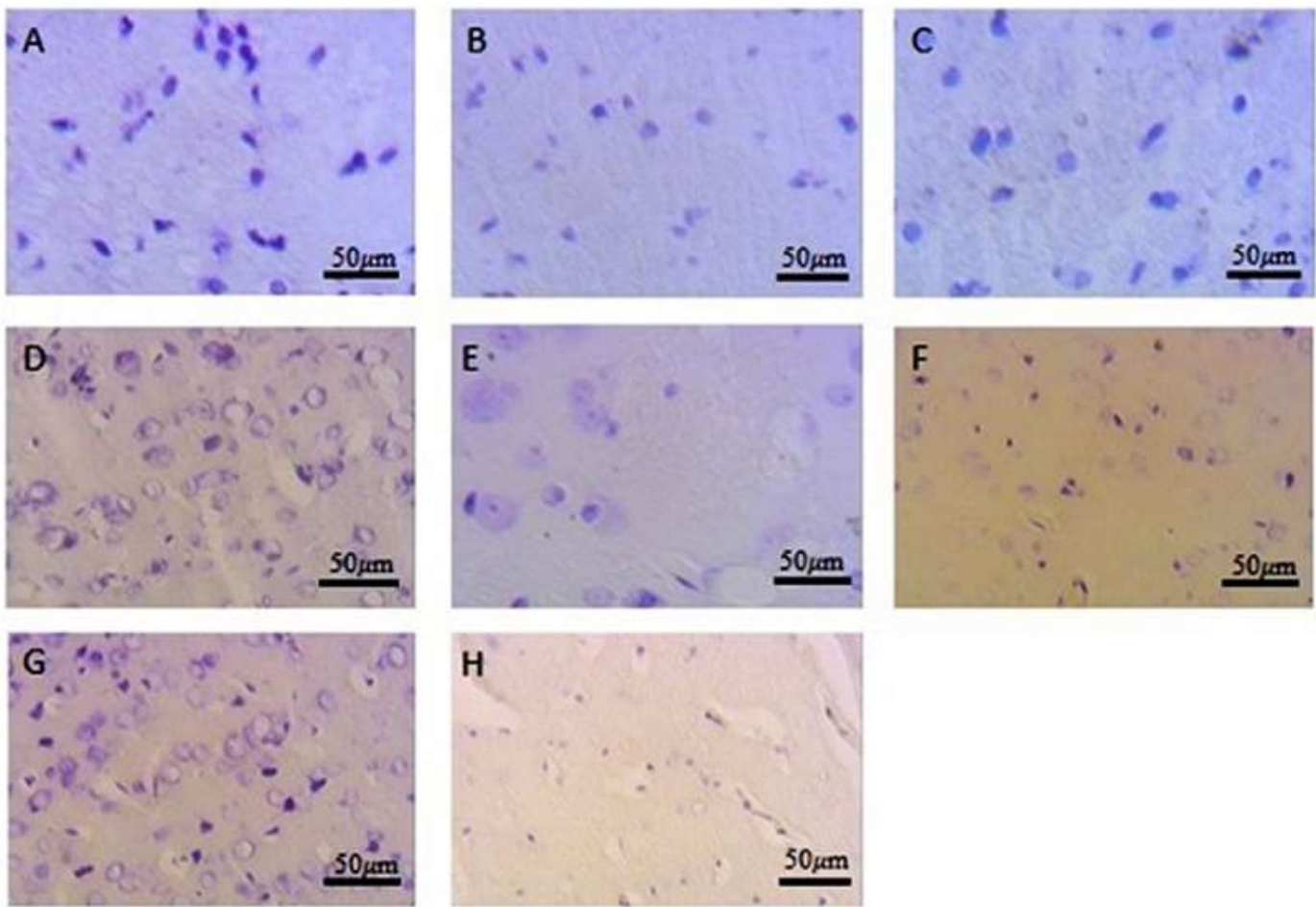

Fig. 4: Photomicrography of the $5 \mu \mathrm{m}$ sections of the rats' striatum in the groups CSI (A), CSS (B), SI (C), SS (D), TI-1 (E), TS1 (F), TI-2 (G) and TS-2 $(\mathrm{H})$, respectively. Scale bars represent $50 \mu \mathrm{m}$ (magnification: $\times 100$ ) 

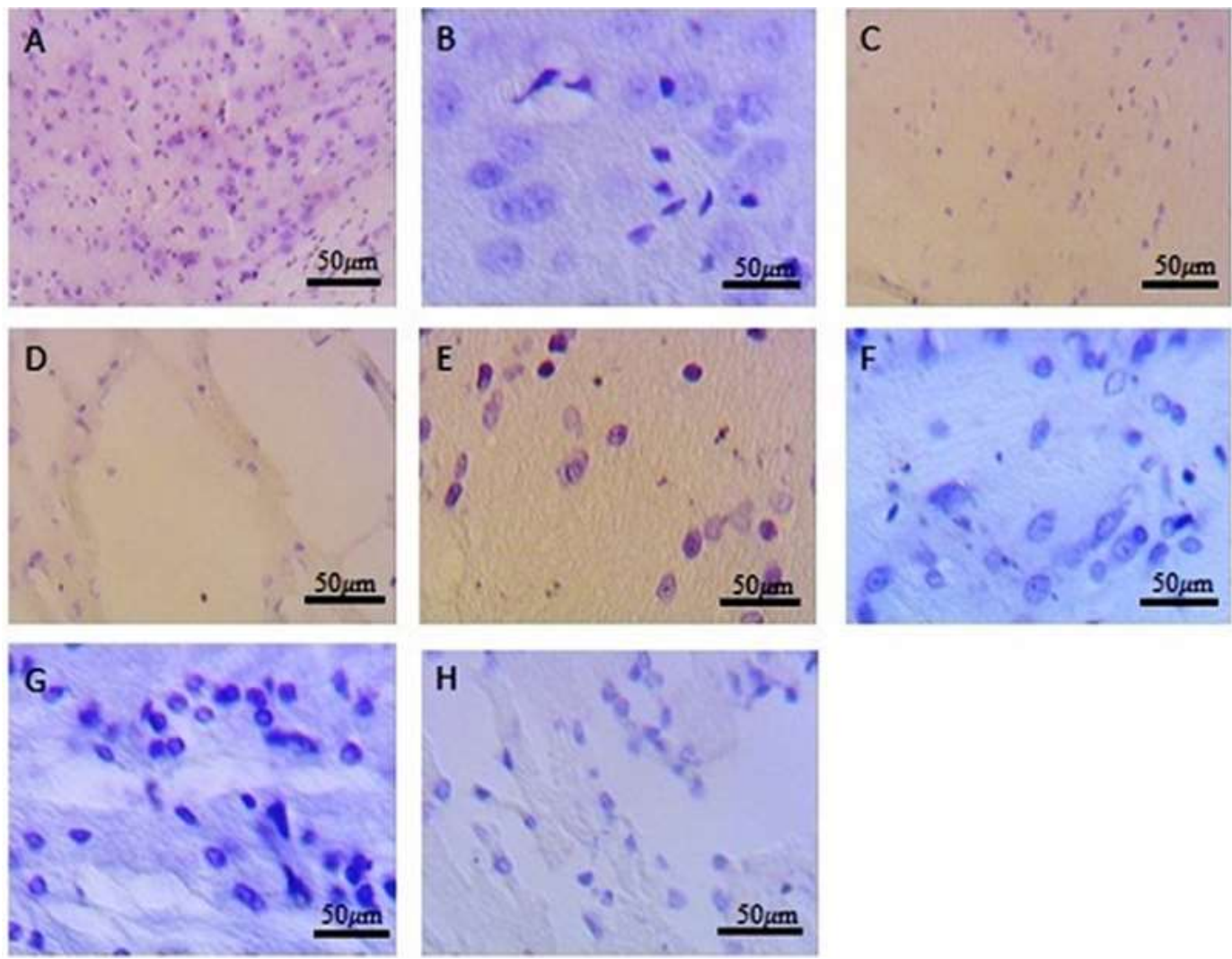

Fig. 5:Photomicrography of the $5 \mu \mathrm{m}$ sections of the rats' hippocampus in the groups CSI (A), CSS (B), SI (C), SS (D), TI-1 (E), TS1 (F), TI-2 (G) and TS-2 (H), respectively. Scale bars represent $50 \mu \mathrm{m}$ (magnification: $\times 100)$

Regarding the total number of neurons in the striatum, a significant difference $(p=0.0181 ; \mathrm{F}=2.6477)$ was also observed. The means of the groups were: CSI = $23 \pm 2.6481 ; \mathrm{CSS}=15.5 \pm 1.4$; $\mathrm{SI}=21.5 \pm 2.246 ; \mathrm{SS}=$ $20.5 \pm 2.8008$; TI- $1=18 \pm 1.2543$; TS- $1=20.5 \pm 1.7008$; TI$2=21 \pm 1.5489$; and TS $-2=13 \pm 0.86086$.

The total mean of neurons in the hippocampus indicated a significant difference $(p=0.0146 ; \mathrm{F}=$ $2.751)$. The means of the groups were: $\mathrm{CSI}=28 \pm 3,2458$; $\mathrm{CSS}=16 \pm 2.4184 ; \mathrm{SI}=12 \pm 3.9721 ; \mathrm{SS}=11.5 \pm 0.76376$; $\mathrm{TI}-1=17.5 \pm 1.0832 ; \mathrm{TS}-1=23.5 \pm 3.0045 ; \mathrm{TI}-2=$ $18 \pm 2.1253$; and TS-2 = 19 \pm 2.3371 .

The histological analysis of the cerebral cortex, striatum and hippocampus of the groups is illustrated below in the photomicrographs (Fig. 3 to 5).

\section{Discussion}

The present study found that the animals submitted to high-intensity training had greater lesions in the cerebral cortex and striatum and their motor performance was also hampered. Curcumin benefited neuronal tissue, promoting neuroprotection in the surrounding area of cerebral ischemia.

Some studies have already demonstrated the efficacy of moderate physical exercises before cerebral ischemia in rats, reducing the area of ischemic injury and increasing collateral irrigation of the brain, as in the studies conducted by Zhang et al. (2012; Damázio et al., 2014; 2015). In the present study, we observed a greater area of brain injury in the groups of animals that performed highintensity exercises before the brain injury.

The groups of animals TIC-1, S, CS and TI-1 obtained better motor performance in the functional tests, demonstrating that the animals that performed high-intensity-resistance exercises, the sedentary group and the animals that received intraperitoneal injections of curcumin had benefits in the motor tests. On the other hand, some studies conducted with humans have shown that high-intensity exercises can cause muscular stress (Place et al., 2015).

There was higher neuronal density in the hippocampus of the animals of the trained groups and the group submitted to injections of curcumin. Therefore, it is possible to infer that the high-intensity physical training favored the neurogenesis in this cerebral region, which is located more deeply in the brain. According to Souza (2012), curcumin has the ability to promote neuroprotective effects and has antimicrobial, anti-inflammatory and antioxidant properties. This way, curcumin had a neuroprotective 
effect, benefiting the animals that received intraperitoneal injection prior to cerebral ischemia. According to Sueth-Santiago et al. (2015), curcumin can have an effect in different systems, such as immunology and inflammation control, due to its chemical and molecular structure.

In addition, the motor performance of the groups of animals trained with high-intensity exercises (specifically muscle strength) worsened after the exercises and curcumin promoted neuroprotection and improved the motor performance of the animals.

\section{Conclusion}

It was concluded that the animals of the sedentary group and the group that received curcumin showed better motor performance and higher neuronal density in the evaluated areas, demonstrating that the high intensity physical exercise increased the brain injury and worsened the motor performance of the animals.

\section{Authors Contributions}

Karine Sthéfany Serpa Amaral Dias, Jonas Augusto Ramos, Amanda Augusta Santos, Andressa Vallotti Balieri, Bruno Mattiello Gomes, Bethânia Ferreira Nascimento, Luiz Guilherme Barbosa, Renan de Araújo Costa, Vinícius Sacramento Resende and Yuri César Silva: Data collect, writing of the article, data analysis, the experiments.

Flávia Carmo Horta Pinto and Laila Cristina Moreira Damázio: Review of the article, correction, writing of the article, experimentation, data analysis.

\section{Conflicts of Interest}

All authors affirm the inexistence of conflicts of interest in this study.

\section{References}

ACSM, 1998. A quantidade e o tipo recomendados de exercícios para o desenvolvimento e a manutenção da aptidão cardiorrespiratória e muscular em adultos saudáveis. Rev. Bras. Med. Esporte Scielo, 4: 96-106. DOI: $10.1590 / \mathrm{S} 1517-86921998000300005$

Cassilhas, R.C., I.T. Reis, D. Venâncio, I. Fernandes and S. Tufik et al., 2013. Animal model for progressive resistance exercise: A detailed description of model and its implications for basic research in exercise. Motriz, 19: 178-184.

DOI: $10.1590 /$ S1980-65742013000100018

Damázio, L.C.M., R.T.R. Melo, M.C. Lima, V.G. Pereira and R.I.M.A. Ribeiro et al., 2015. Exercício físico promove neuroproteção estrutural e funcional em ratos com isquemia cerebral. Rev. Neurocienc, 23: 581-588. DOI: 10.4181/RNC.2015.23.04.1051.08p
Damázio, L.C.M., R.T.R. Melo, M.C.L. Lima, H.B. Santos and R.I.M.A. Ribeiro et al., 2014. Effects of exercise prior or after ischemia on the density of neurons and astrocytes in the brain of rats. Am. J. Neurosci., 5: 18-25. DOI: 10.3844/amjnsp.2014.18.25

Ding, Y., J. Li, Q. Lai, J.A. Rafols and X. Luan et al., 2004. Motor balance and coordination functional outcome in rat with cerebral artery occlusion training enhances transient middle. Neuroscience, 123: 667-674.

DOI: 10.1016/j.neuroscience.2003.08.031

Ding, Y.C., Y.D. Zhou, Q. Lai, J. Li and H. Park et al., 2002. Impaired motor activity and motor learning function in rat with middle cerebral artery occlusion. Behav. Brain Res., 132: 29-36. DOI: $10.1016 / \mathrm{S} 0166-4328(01) 00405-3$

Hornberger Jr., T.A. and R.P. Farrar, 2004. Physiological hypertrophy of the FHL muscle following 8 weeks of progressive resistance exercise in the rat. Can. J. Applied Physiol., 29: 16-31. PMID: 15001801

Kim, D.S., J.Y. Kim and Y. Han, 2012. Curcuminoids in neurodegenerative diseases. Recent Pat. CNS Drug Discov., 7: 184-204.

DOI: $10.2174 / 157488912803252032$

Kulkarni, S.K. and A. Dhir, 2010. An overview of curcumin in neurological disorders. Ind. J. Pharm. Sci., 72: 149-154. DOI: 10.4103/0250-474X.65012

Lim, S.H., J.S. Lee, J.I. Lee, S. Im and Y.J. Ko et al., 2008. The quantitative assessment of functional imparment and its correlation to infarct volume in rats with transient middle cerebral artery occlusion. Brain Res., 1230: 303-309.

DOI: 10.1016/j.brainres.2008.07.002

Matteucci, A., R. Cammarota, S. Paradisi, M. Varano and M. Balduzzi et al., 2011. Curcumin protects against NMDA-induced toxicity: A possible role for NR2A. IOVS, 52: 1070-1077.

DOI: $10.1167 /$ iovs.10-5966

Peixinho-Pena, L.F., J. Fernandes, A.A. De Almeida, F.G. Novaes Gomes and R. Cassilhas et al., 2012. A strength exercise program in rats with epilepsy is protective against seizures. Epilepsy Behav., 25: 323-328. DOI: 10.1016/j.yebeh.2012.08.011

Pinheiro, H.A., 2011. Uso da bengala padrão na reabilitação da marcha de pacientes com sequela de acidente vascular cerebral. Rev. Neurocienc, 19: 358-64.

Place, N., N. Ivarsson, T. Venckunas, D. Neyroud and M. Brazaitis et al., 2015. Ryanodine receptor fragmentation and sarcoplasmic reticulum $\mathrm{Ca} 2+$ leak after one session of high-intensity interval exercise. PNAS, 112: 15-15. DOI: 10.1073/pnas.1507176112

Ringman, J.M., S.A. Frautschy, E. Teng, A.N. Begum and J. Bardens et al., 2012. Oral curcumin for Alzheimer's disease: tolerability and efficy in a 24week randomized, double blind, placebo controlled study. Alzheimeres Res. Ther., 4:1-8.

DOI: $10.1186 /$ alzrt146 
Scorza, F.A., R.M. Arida, R.M. Cysneiros, C.A. Scorza and M. Albuquerque et al., 2005. Estudo qualitativo da formação hipocampal de animais hipertensos com epilepsia. Arq. Neuro-Psiquiatr., 63: 283-288. DOI: $10.1590 / S 0004-282 X 2005000200015$

Sociedade Brasileira de Doenças Cerebrovasculares. http://www.sbdcv.org.br/publica_avc.asp

Souza, C.M., 2012. Efeito neuroprotetor da curcumina sobre o estresse oxidativo, inflamação, memória e dano neuronalde ratos submetidos à isquemia cerebral transitória [Tese de doutorado]. PósGraduação em Ciências Médicas da UFC, Fortaleza.

Sueth-Santiago, V., G.P. Mendes-Silva, D. Decoté-Ricardo and M.E.F. De Lima, 2015. Curcumina, o pó dourado do açafrão-da-terra: Introspecções sobre química e atividades biológicas. Quim. Nova, 38: 538-552.

Tardini, D.M.S., W.B. Yoshida, E.L.B. Novelli and J.L. Sequeira, 2003. Avaliação de dois modelos experimentais de isquemia e reperfusão cerebral em ratos com oclusão temporária carotídea associada ou não à oclusão vertebral. Acta Cir. Bras., 18: 502-508. DOI: 10.1590/S0102-86502003000600004
Telles, M.V.L., M.E.P. Nobre, L.P. Alencar, K.P. De Siqueira and A.M.F.S. Borges et al., 2014. Prenatal curcumin administration reverses behavioral and neurochemical effects and decreases iNOS and COX-2 expressions in ischemic rat pups. Int. J. Brain Sci. DOI: 10.1155/2014/907581

Trindade, A.P.N., M.A. Barboza, F.B. Oliveira and A.P.O. Borges, 2011. Influência da simetria e transferência de peso nos aspectos motores após acidente vascular cerebral. Rev. Neurocienc, 19: 61-67.

Xie, L., X.K. Li, N. Funeschima-Fuji, H. Kimura and Y. Matsumoto et al., 2009. Amelioration of experimental autoimmune encephalomyelitis by curcumin treatment through inhibition of IL-17 production. Int. Immunopharmacol., 9: 575-581. DOI: 10.1016/j.intimp.2009.01.025

Zhang, P., Q. Zhang, H. Pu, Y. Wu and Y. Bai et al., 2012. Very early-initiated physical rehabilitation protects against ischemic brain injury. Front Biosci., 4: 2476-89. DOI: 10.2741/e559 